\title{
Optimizing the design parameters of a packed column aerator for VOC removal: A real case study on polluted ground water
}

\author{
Abdukarem I Amhamed,' Elmahboub A Edredera, ${ }^{2}$ Kavithaa Loganathan,' Mansour M Emtir ${ }^{3}$ \\ 'Qatar Environment and Energy Research Institute (QEERI), Hamad Bin Khalifa University, Qatar \\ ${ }^{2}$ National Oil Corporation ,Tripoli , Libya \\ ${ }^{3}$ Libyan Petroluem Institute, Tripoli, Libya
}

Correspondence: Abdukarem I Amhamed, P.O. Box 34II0, Qatar Environment and Energy Research Institute (QEERI), Hamad Bin Khalifa University (HBKU), Qatar Foundation, Doha, Qatar,Tel +97444546I09, Fax +974 4454I528, Email aamhamed@hbku.edu.qa

Received: October 17, 2017 | Published: October 26, 2017

Copyright@ 2017 Amhamed et al. This is an open access article distributed under the terms of the Creative Commons Attribution License, which permits unrestricted use, distribution, and reproduction in any medium, provided the original author and source are credited.

\begin{abstract}
Volatile organic compounds such as aliphatic and aromatic hydrocarbons are carried through pipelines in oil and gas industry. The leakage of these compounds from pipelines mixes with ground water. The ground water contamination poses hazards to public health that limits the reuse. It's essential to remove Volatile organic compounds (VOC's) from contaminated water for a sustainable reuse of ground water resources. There are various methods for the effective removal of (VOC's) from water. This article discusses about the optimized use of packed column aerator for high volume flow applications. Various design, physical parameters were used to evaluate and optimize the performance in an economical way are also discussed.
\end{abstract}

Keywords: Contaminated Ground water- Volatile organic compounds (VOC's) removal-packed column air stripper/aeration-design-economic evaluations

\section{Introduction}

The presence of volatile organic compounds (VOC's) in ground water sources reduces the possibilities of water reuse. ${ }^{1-4}$ Moreover, when the water is reused for potable or irrigation purposes, the contamination of VOC's from ground water sources pose hazards to public health. ${ }^{5-8}$ This article will discuss about the design optimizations of a packed bed aerator for VOC removal in ground water. The packed tower aeration is a widely-used air stripping technology for the polluted groundwater treatment for large volumes of water at high flow rates. ${ }^{9,10}$ Spray towers, bubble aerators, low profile aerators, and surface aerators are other air stripping technologies primarily used at low flow rates $(<100 \mathrm{gpm})$. Typically, the packed air stripping system consist of a spray nozzle to distribute contaminated water from the top of the column over the packing in the tower, a fan to force air counter current to the water mass flow rate, and a sump to collect decontaminated water from the bottom of the tower. The high VOC removal efficiencies at very low pressure drops can be achieved with the packed bed aeration systems. ${ }^{11,12}$ Despite its merits, the knowledge gap still exists in the area of air stripper performance optimizations. ${ }^{13}$ The optimizations of height of the packing material, the diameter of tower, the air/water loading rates and water temperature with respect to influent concentration of contaminants will improve the efficiency of VOC removal and the performance. Stripping factor is a representation of capacity for mass transfer relative to equilibrium condition in the packed bed aerator. This work provides a design and economic evaluations of using different packing materials. In this study, experiments were conducted using the contaminated ground water from Libyan oil fields. The design and economic evaluations of a packed bed aerator for VOC removal were carried out by using Air Stripper Design and Costing Program (ASDC). The design parameters such as stripping factor and type of packing material, and the physical parameters such as tower diameter air to water ratio, height of the packing material were evaluated to achieve the desired VOC removal efficiency.

\section{Materials and methods}

For a packed air-stripping unit, the design parameters are stripping factor, pressure drop, and type of packing elements. The physical parameters to be estimated during the design are the tower diameter, air-to-water ratio, height of packing material needed to achieve targeted removal efficiency. The stripping factor (and hence air to water ratio) and the packing height can affect the VOC removal performance and the effluent quality.

The procedure of air stripper design presented herein is based on mass transfer theory:

Height of Transfer Unit (HTU): $=\frac{L_{m}}{K_{L} a C_{T}}$.
Submit your Article | www.ologypress.com/submit-article

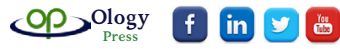

Citation: Amhamed Al, Edredera EA, Loganathan K, Emtir MM. Optimizing the design parameters of a packed column aerator for VOC removal:A real case study on polluted ground water.J Oil Gas Petrochem Sci. (2017);0(0): I-4. DOI: 10.3088 I/jogps.0000 I 
Number of Transfer Unit (NTU): $=\left[\frac{R}{R-1}\right] \ln \left[\frac{X_{\text {in }} / X_{\text {out }}(R-1)+1}{R}\right]$
(2)

Packing Height $(Z)=$ HTU x NTU

Stripping factor $(\mathrm{R})=\left(\frac{G_{m}^{*} \rho_{L}}{L_{m}^{*} \rho_{c}}\right) * \frac{H_{A}}{P_{T}}$
Details of the general design procedures can be found in literature. ${ }^{14}$ The design and the operational parameters of a typical packed bed aeration system are summarized Table 1 . The techno-economic study determines the trade-off between air/water ratio and tower volume as a function of air pressure losses and targeted packing system. Furthermore, the design optimization process is targeted to reduce the vessel and equipment size at a pressure drop in order to reduce the energy requirements. The required VOC removal efficiencies and the final product water quality will affect the liquid loading rate, packing dimensions, and air/water ratio.

Table I Packed Tower design and operation parameters

\begin{tabular}{|c|c|c|}
\hline Factors & $\begin{array}{l}\text { Effect of Increase }(\uparrow) \text { Parameter on } \\
\text { Operation and Cost, assuming no change } \\
\text { in tower design }\end{array}$ & $\begin{array}{l}\text { Effect of increase }(\uparrow) \text { parameter on tower } \\
\text { design, assuming removal performance } \\
\text { maintained }\end{array}$ \\
\hline Liquid capacity & $\downarrow$ Removal Performance & $\uparrow$ Tower Height (HTU) \\
\hline Air/Water Ratio (AWR) & $\uparrow$ Removal Performance & $\downarrow$ Packing Volume \\
\hline Water Temperature & $\begin{array}{l}\uparrow \text { Removal Performance } \\
\text { Heating Cost }\end{array}$ & $\downarrow$ Packing Volume \\
\hline Henry's Constant & $\uparrow$ Removal Performance & $\downarrow$ Packing Volume \& - AWR \\
\hline Packing Type and Size & $\uparrow$ The dimension\& $\downarrow$ Removal Performance & $\begin{array}{l}\uparrow \text { The dimensions \& + Packing Vol } \downarrow \\
\text { Pressure Drop }\end{array}$ \\
\hline Pressure Drop/Depth & $\begin{array}{l}\uparrow \text { Removal Performance } \\
\text { Blower Cost }\end{array}$ & $\uparrow \mathrm{AWR}$ \\
\hline
\end{tabular}

( $\uparrow$ Increase \& $(\downarrow)$ decrease

Air Stripper Design and Costing (ASDC) software was used for the design and cost optimizations. Some of the features of this software include modifications of some cost factors such as packing material unit cost and electricity rate.

The total annual cost is given by the following equation:

Annual cost $=$ operating cost + total capital cost

$$
\left(\frac{i / 100}{1-\left(1+\frac{i}{100}\right)^{-y}}\right)
$$

Total Capital cost $=$ Total Direct Cost + Total Indirect Cost

Total Direct Cost $=$ Process Equipment Cost + Support Equipment Cost (7)

Where $\mathrm{i}$ is the interest rate in \% which is assumed to be $10 \%$, and y is the time in years also assumed to be 20 years. Details of the cost model can be found in literature (Dzombak et al. 1993)

The contaminated groundwater samples were taken from fields in Libya. The water was contaminated with BETX (Benzene, Ethylbenzene, Toluene, and Xylene) due to surrounding pipeline leaks. Samples were stored at $4^{\circ} \mathrm{C}$ for packed bed aeration studies. Aerator packed with a plastic type packing material, Nor-Pac 5/8", was used for testing the polluted groundwater. For this case study the water flow rate was set to $100 \mathrm{gpm}$, ambient pressure to $1 \mathrm{bar}$ and the pressure drop of $50 \mathrm{~N} / \mathrm{m}^{2} / \mathrm{m}$. The water quality data and desired concentration values of the VOCs are listed in Table 2.

Table 2 The water quality data and desired concentration values of the VOCs in the contaminated groundwater

\begin{tabular}{llll}
\hline Contaminants & Formula & $\begin{array}{l}\text { Concentration } \\
(\mathbf{p p m})\end{array}$ & $\begin{array}{l}\text { Desired } \\
\text { Concentration } \\
(\mathbf{p p b})\end{array}$ \\
\hline Benzene & $\mathrm{C}_{6} \mathrm{H}_{6}$ & 56.0 & 5.0 \\
Ethylbenzene & $\mathrm{C}_{8} \mathrm{H}_{10}$ & 1.3 & 0.1 \\
Toluene & $\mathrm{C}_{7} \mathrm{H}_{8}$ & 31.0 & 2.4 \\
I, 2-xylene & $\mathrm{C}_{8} \mathrm{H}_{10}$ & 13.0 & 3.6 \\
I, 3-xylene & $\mathrm{C}_{8} \mathrm{H}_{10}$ & 7.1 & 0.5 \\
\hline
\end{tabular}

Stripping factor (SF) is defined as the ratio of the air flow rate actually used to the minimum required for air stripping. It is a very important factor to be considered in order to minimize the capital and operating costs of a packed bed aeration system. Range of stripping factor values from 2 to 4 at water temperature $30^{\circ} \mathrm{C}$ and water flow rate 100 $\mathrm{gal} / \mathrm{min}$ were studied. 
The influence of temperature on the VOC's concentration removal was considered within a temperature range of $20-35^{\circ} \mathrm{C}$ and at constant water flow rate $(100 \mathrm{gpm})$, constant stripping factor $(\mathrm{R}=2.5)$.

The structured column packing consists of vertical sheets of ceramic/ metal/plastic material with an open honeycomb structure providing a relatively high surface area. The performance of aerator packing bed depends on the packing shape, materials and the packing size. Selection of size and shape involves a trade-off between low packing factor, and large surface area. With a minimum head loss and high interfacial area, the overall mass transfer rate can be maximized. The total annual costs for the three types of packing materials (e.g. super Intalox, Nor-Pac 5/8, pall ring) for stripping factor range of 2 to 8 were studied. Benzene was chosen as the key design contaminant, water temperature was set at $30^{\circ} \mathrm{C}$, and water flow rate was at 100 gallons per minute.

\section{Results}

\section{Effect of stripping factor}

The effluent concentrations of VOC's for different stripping factors are shown in Table 3. Given a sufficiently tall column, stripping factors of $>1$ was selected to ensure there is enough gas for a complete removal of VOC's. With the stripping factor (SF) of 2 the desired benzene concentration of $5 \mathrm{ppb}$ was achieved and no further decrease was observed for SF's 2.5, 3.0 and 4.0. For ethyl benzene, the target concentration was achieved with SF 2. Further increase in SF decreased the ethyl benzene removal efficiency. The desired toluene removal was achieved for SF's 2 and 2.5. However, toluene concentrations were higher than the target value for SF's 3.0 and 4.0. For 1, 2-Xylene, the target concentration was only achieved for SF 3.0. On the other hand, the target concentration of 1,3-xylene was within the range of $0.5 \mathrm{ppb}$ for the SF's 2.0, 2.5 and 3.0.

Table 4 presents the design parameters air/water ratio and overall mass transfer coefficients for each stripping factor. The air water ratio and tower diameter increases with SF factor while the packing height and tower height decreases with the SF increases.

Table 3 The effluent concentration ( $\mathrm{ppb}$ ) of VOCs for different stripping factors $(\mathrm{R})$

\begin{tabular}{lllll}
\hline Contaminants & SF 2 & SF 2.5 & SF 3 & SF 4 \\
\hline Benzene & 5.0 & 5.0 & 5.0 & 5.0 \\
Ethylbenzene & 0.02 & 0.04 & 0.06 & 0.1 \\
Toluene & 1.44 & 2.03 & 2.43 & 2.93 \\
I, 2-xylene & 4.69 & 3.95 & 3.61 & 3.28 \\
I, 3-xylene & 0.21 & 0.38 & 0.52 & 0.71 \\
\hline
\end{tabular}

Table 4 Design parameter results for different stripping factors

\begin{tabular}{lllll}
\hline Parameter & SF 2 & SF 2.5 & SF 3 & SF 4 \\
\hline Tower diameter, D (m) & 0.47 & 0.5 & $0.5 \mathrm{I}$ & 0.59 \\
Packing height, Z $(\mathrm{m})$ & 14.53 & $1 \mathrm{l} .96$ & $10.6 \mathrm{I}$ & 8.88 \\
Tower height, H (m) & 18.89 & 15.55 & 13.8 & 11.54 \\
Air / water ratio & 8.44 & 10.55 & 12.65 & 16.87 \\
$\mathrm{KLa}(\mathrm{I} / \mathrm{s})$ & $4.235 \mathrm{E}^{-2}$ & $4.013 \mathrm{E}^{-2}$ & $3.836 \mathrm{E}^{-2}$ & $3.178 \mathrm{E}^{-2}$ \\
\hline
\end{tabular}

\section{Effect of water temperature}

The results in terms of effluent concentration (ppb) of VOC are shown in Table 5. As the water temperature is increased, the better VOC the removal efficiencies were achieved. The optimum temperature for 1 , 2-xylene was found to be $25^{\circ} \mathrm{C}$ and as the temperature is increased no significant change in 1,2-xylene concentration was observed. Figure 1 clearly shows that $\mathrm{KL}$ values increases as the water temperature is increased.

The design parameters, air/water ratios and mass transfer coefficients are shown in Table 6 . The change in water temperature has an effect on the design output parameters (Table 6), and overall mass transfer coefficient. Increasing water temperature leads to a decrease in packing height, tower height, and tower diameter.

Table 5 Effect of water temperature on VOC concentration (ppb) at SF 2.5

\begin{tabular}{lllll}
\hline Contaminants & $\mathbf{2 0 ^ { \circ } \mathbf { C }}$ & $\mathbf{2 5}^{\circ} \mathbf{C}$ & $\mathbf{3 0 ^ { \circ } \mathbf { C }}$ & $\mathbf{3 5}^{\circ} \mathbf{C}$ \\
\hline Benzene & 5 & 5 & 5 & 5 \\
Ethylbenzene & 0.06 & 0.04 & 0.04 & 0.04 \\
Toluene & 2.4 & 2.05 & 2.03 & 2.01 \\
I,2-xylene & 6.17 & 3.92 & 3.95 & 3.98 \\
I-3xylene & 0.5 & 0.39 & 0.38 & 0.37 \\
\hline
\end{tabular}

Table 6 Design parameter results for different water temperatures

\begin{tabular}{lllll}
\hline Parameter & $\mathbf{2 0}{ }^{\circ} \mathbf{C}$ & $\mathbf{2 5}^{\circ} \mathbf{C}$ & $\mathbf{3 0} \mathbf{C}$ & $\mathbf{3 5}^{\circ} \mathbf{C}$ \\
\hline $\begin{array}{l}\text { Tower diameter, } \\
\text { D (m) }\end{array}$ & 0.57 & 0.5 & 0.5 & 0.49 \\
$\begin{array}{l}\text { Packing height, } \\
\text { Z (m) }\end{array}$ & $15.4 \mathrm{I}$ & 13.84 & 11.96 & 10.44 \\
$\begin{array}{l}\text { Tower height, H } \\
(\mathrm{m})\end{array}$ & 20.03 & 17.99 & 15.55 & 13.58 \\
$\begin{array}{l}\text { Air / water ratio, } \\
\text { KLa (I/s) }\end{array}$ & 14.49 & 10.55 & 10.55 & 10.55 \\
\hline
\end{tabular}

Comparison of total annual cost based on different packing materials

It can be seen from Figure 2, that the sharp decrease was found in the cost for SF's from 2 to 4 and the annual capital cost remains steady with the SF's 5 to 8 .

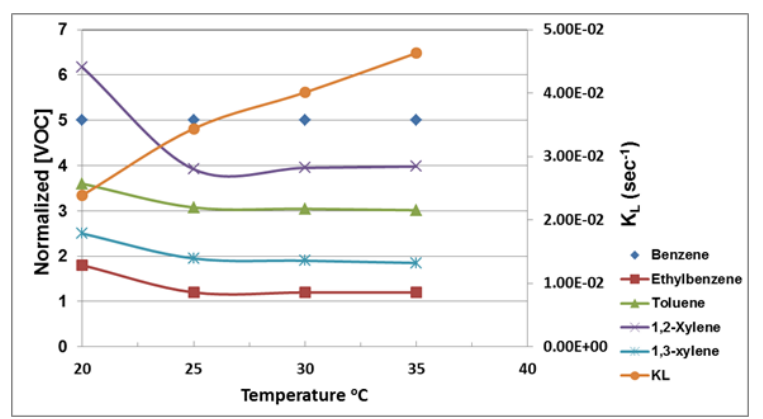

Figure I The effect of water temperature on VOC concentrations (primary $y$-axis) and $K_{L}$ (secondary $y$-axis). 


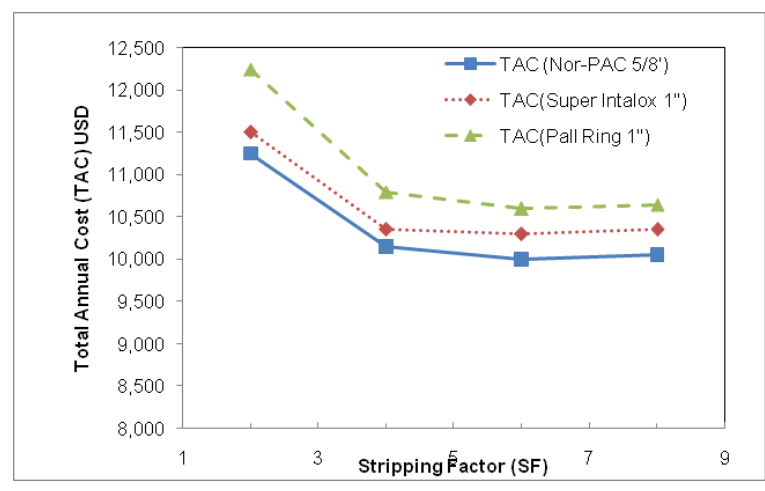

Figure 2 The effect of stripping factors of commercial packing materials on total annual cost (TAC).

\section{Discussion}

Results of 1, 2-xylene (Table 3) indicates that the increase in air to water ratio increases the VOC removal efficiency. When the air flow rate is increased, (Table 4) the interfacial area increases and the gasphase resistance decrease, thereby increasing the efficiency of the mass transfer. For Benzene, SF2 results in $99.99 \%$ of removal from the initial benzene concentration of $56.0 \mathrm{ppm}$. With the increase in air flow rates and SF's, a steady removal of $99.99 \%$ was achieved for benzene. A similar trend, as benzene, was observed for ethyl benzene, toluene and 1,3-xylene. The optimum packing height for the SF 2.5 was found to be $11.96 \mathrm{~m}$. Parameters such as pressure drop, packing volume, and the total break power was optimized along with the packing height. For a given air water ratio, the lower packing height requires a larger pressure drop and less total break horsepower to achieve the desired removal efficiency (Mohammed Evuti Abdullahi, 2014). Figure 1 shows that the change of water temperatures influences physical properties of both the water and gas, and therefore has a significant impact on the mass transfer coefficient. When the water temperature was increased, both the water viscosity and surface tension of air bubbles were reduced thus helping the coalescence process. Moreover, the viscosity decrease can reduce the thickness of the stagnant film at the gas liquid interface, thereby lowering the mass transfer resistance and increasing the diffusion coefficient. These effects give rise to the steady increase in KL values as the water temperature increased. Also, it can be seen that simulation using the Nor-Pac 5/8" packing gave the minimum costs compared to Super Intalox Saddle and Pall-Ring 1" packings. The type and shapes of packing materials determine the pressure drop in the packed bed aeration process. This indicates Nor-Pac 5/8" is the optimum packing for the case considered in this work.

\section{Conclusion}

The increase of air to water ratio increases the VOC removal efficiency of the packed column aerator. For the stated pollutant levels in ground water, the best SF value was found to be 2.5 . Temperature has significant effect on physical properties of both water and gas, and thereby influences the mass transfer co-efficient of packed column aerators. The types and shapes of packing materials determine the pressure drop, and Nor-Pac 5/8" was found to be the optimum packing for this case study. It's therefore important to optimize the packed column aerator especially for high flow rates for the economic and effective reuse of the ground water. Future work will be aimed at developing an innovative process design to capture the VOC's that were carried by the air medium.

\section{Acknowledgement}

The authors would like to acknowledge the Qatar Environment and Energy Research Institute (QEERI), Hamad Bin Khalifa University, Doha, Qatar for supporting the Water Grand Challenges Portfolio. Authors like to acknowledge NOC, Libya for funding the Ground water projects.

\section{References}

1. Loganathan K, Chelme-Ayala P, Gamal El-Din M. Pilot-scale study on the treatment of basal aquifer water using ultrafiltration, reverse osmosis and evaporation/crystallization to achieve zero-liquid discharge. J Environ Manage. 2016;165:213-223.

2. Pal A, He Y, Jekel M, et al. Emerging contaminants of public health significance as water quality indicator compounds in the urban water cycle. Environ Int. 2014;71:46-62.

3. Postigo C, Martinez DE, Grondona S, Miglioranza KSB. Reference Module in Earth Systems and Environmental Sciences, Elsevier. 2017.

4. Tornero V, Hanke G. Chemical contaminants entering the marine environment from sea-based sources: A review with a focus on European seas. Mar Pollut Bull. 2016;112(1-2):17-38.

5. Boyes WK, Bushnell PJ, Crofton KM, et al. Neurotoxic and pharmacokinetic responses to trichloroethylene as a function of exposure scenario. Environ Health Perspect. 2000;108 Suppl 2:317-322.

6. Herpin G, Gargouri I, Gauchard GC, et al. Effect of Chronic and Subchronic Organic Solvents Exposure on Balance Control of Workers in Plant Manufacturing Adhesive Materials. Neurotox Res. 2009;15(2):179-186.

7. Huang B, Lei C, Wei C, et al. Chlorinated volatile organic compounds ( $\mathrm{Cl}-$ VOCs) in environment - sources, potential human health impacts, and current remediation technologies. Environ Int. 2014;71:118-138.

8. WHO Guidelines for Drinking-water Quality, World Health Organization, Geneva, Switzerland. 2011.

9. Jiao W, Luo S, He Z, et al. Applications of high gravity technologies for wastewater treatment: A review. Chemical Engineering Journal. 2017;313:912-927.

10. Shestakova M, Sillanpää M. Removal of dichloromethane from ground and wastewater: A review. Chemosphere. 2013;93(7):1258-1267.

11. Aydin Berenjian, Natalie Chan, Hoda Jafarizadeh Malmiri. Volatile Organic Compounds Removal Methods: A Review. American Journal of Biochemistry and Biotechnology. 2012;8(4):220-229.

12. Mohamed Ali El-Behlil, El-Gezawi Sead M, Sabri A Adma. Volatile Organic Chemicals Removal from Contaminated Water using Air Stripping Low Profile Sieve Tray Towers. Sixteenth International Water Technology Conference. 2012.

13. Mohammed Evuti Abdullahi, Mohd Ariffin Abu Hassan, Zainura Zainon Noor, et al. Application of a packed column air stripper in the removal of volatile organic compounds from wastewater. Rev Chem Eng. 2014;30(5):1.

14. Dzombak DA, Roy Sujoy B Fang, Hung-Jung. Air-Stripper Design and Costing Computer Program. American Water Works Association. 1993;85(10):63-72.
Citation: Amhamed Al, Edredera EA, Loganathan K, Emtir MM. Optimizing the design parameters of a packed column aerator forVOC removal:A real case study on polluted ground water.J Oil Gas Petrochem Sci. (2017);0(0): I-4. DOI: $10.30881 /$ /jogps.00001 